\title{
EFEITOS DO TRATAMENTO DE PARTÍCULAS E ACELERADORES DE ENDURECIMENTO NA PRODUÇÃO DE PAINÉIS CIMENTO-MADEIRA DE Hevea brasiliensis
}

\author{
Setsuo Iwakiri ${ }^{1}$, Rosilani Trianoski ${ }^{1}$, Alessandra Monique Weber ${ }^{2}$, Eraldo Antonio Bonfatti Junior ${ }^{2}$, Giuliano \\ Ferreira Pereira ${ }^{2}$, Jessica Aline Bueno ${ }^{2}$, Luana Cechin ${ }^{2}$, Renan Zunta Raia ${ }^{2}$ \\ ${ }^{1}$ Universidade Federal do Paraná, Departamento de Engenharia e Tecnologia Florestal, Curitiba, Paraná, Brasil - setsuo@ufpr.br; \\ rosilani@ufpr.br \\ ${ }^{2}$ Universidade Federal do Paraná, Programa de Pós-Graduação em Engenharia Florestal, Curitiba, Paraná, Brasil - \\ alessandramoniqueweber@gmail.com; bonfattieraldo@gmail.com; Giuliano.giiu@gmail.com; jessica_eim@hotmail.com; \\ luhcechun@gmail.com; renan.raia@hotmail.com
}

Recebido para publicação: 07/04/2017 - Aceito para publicação: 06/09/2017

\begin{abstract}
Resumo
A Hevea brasiliensis (seringueira) é uma espécie nativa da Amazônia e apresenta elevada importância econômica no Brasil, por ser amplamente utilizada na obtenção de latéx para produção de borracha. Os plantios comerciais da Hevea brasiliensis estão localizados principalmente no interior do estado de São Paulo e se encontram ainda na fase de extração de látex, tendo a necessidade de estudos tecnológicos para a utilização da sua madeira ao final do seu ciclo. Na busca por alternativas para uso industrial da sua madeira, esta pesquisa teve como objetivo avaliar o seu potencial para produção de painéis cimento-madeira. Para a produção de painéis experimentais foram empregadas partículas de madeira tratadas por imersão em água fria por 24h, água quente por 6h e hidróxido de sódio $(\mathrm{NaOH})$ por 2 horas; e Cloreto de cálcio $\left(\mathrm{CaCl}_{2}\right)$ e Silicato de Sódio $\left(\mathrm{Na}_{2} \mathrm{SiO}_{3}\right)$ como aceleradores de endurecimento do cimento. Os painéis foram produzidos com densidade nominal de $1,10 \mathrm{~g} / \mathrm{cm}^{3}$, relação madeira cimento de $1: 2,75$, fator água cimento de 0,4 e $3 \%$ de aceleradores de cura. Os ensaios físicos e mecânicos dos painéis indicaram melhores resultados para os painéis produzidos com partículas tratadas em água quente por 6 horas e uso do cloreto de cálcio como acelerador de endurecimento. Os resultados permitem concluir que a madeira de Hevea brasiliensis (RRIM 600) apresenta potencial para a produção de painéis cimento-madeira.

Palavras-chave: Seringueira; plantio florestal; extrativos da madeira; construção civil.
\end{abstract}

\begin{abstract}
Effects of particles treatments and cement accelerator admixture in the wood cement panel production. Hevea brasiliensis (rubber tree) is a native species of the Amazon and has a high economic importance in Brazil, since it is widely used in obtaining latex for rubber production. The commercial plantations of Hevea brasiliensis are located mainly in the São Paulo State and are still in the latex extraction phase, and there is the need for technological studies to use their wood at the end of cycle. In the search for alternatives for industrial use of its wood, this research aimed to evaluate its potential for the production of cement-wood panels. For the experimental panels manufactures were used wood particles treated by immersion in cold water for $24 \mathrm{~h}$, hot water for $6 \mathrm{~h}$ and sodium hydroxide $(\mathrm{NaOH})$ for 2 hours; and Calcium Chloride $\left(\mathrm{CaCl}_{2}\right)$ and Sodium Silicate $\left(\mathrm{Na}_{2} \mathrm{SiO}_{3}\right)$ as curing hardener. The panels were produced with nominal density of $1.10 \mathrm{~g} / \mathrm{cm}^{3}$, wood cement ratio of $1: 2.75$, water cement factor of 0.4 and $3 \%$ of curing hardener. The physical and mechanical tests of the panels indicated better results for the panels produced with particles treated in hot water for 6 hours and the use of calcium chloride as a cement accelerator admixture. The results of the research indicated that the wood of Hevea brasiliensis (RRIM 600) has potential for wood cement panels manufacture.

Keywords: Seringueira; forest plantation; wood extractives; civil construction.
\end{abstract}

\section{INTRODUÇÃO}

O painel cimento-madeira é produzido com a utilização de partículas ou fibras de biomassa vegetal, cimento, água e aditivos químicos, sendo que a consolidação do material ocorre à temperatura ambiente por meio da aplicação de pressão (LATORRACA, 2000). Este tipo de painel apresenta inúmeros atributos favoráveis para utilização na construção civil, devido à alta resistência mecânica, à umidade e ao ataque de agentes biodegradadores, além de apresentar propriedades isolantes e ser virtualmente incombustível (MOSLEMI, 1974).

FLORESTA, Curitiba, PR, v. 47, n. 3, p. 289 - 296, jul. / set. 2017

Iwakiri, S. et al.

ISSN eletrônico 1982-4688

DOI: $10.5380 /$ rf.v47i1.51636 
Devido aos extrativos presentes na madeira, algumas espécies podem apresentar alta inibição ao endurecimento do cimento durante o processo de produção de painéis cimento-madeira (SANTOS et al., 2012). Para minimizar estes efeitos negativos e não retardar o endurecimento do cimento podem ser empregados aditivos químicos como o Cloreto de cálcio, Silicato de sódio e Hidróxido de sódio, em mistura com o cimento e madeira na produção de painéis (LATORRACA, 2000). Embora o cloreto de cálcio seja corrosivo ao aço e não ser mais usado no concreto armado, este produto é mais empregado na produção de painéis cimento-madeira, tendo em vista a sua relação custo-benefício e não haver contato direto com o aço na sua composição.

Além dos aditivos químicos, tratamentos de partículas podem ser realizados para extrair substâncias químicas inibidoras de cura, sendo que os métodos mais empregados são: (a) imersão das partículas em água fria por 24 horas; (b) imersão em água quente por 6 horas; e imersão em solução de hidróxido de sódio $(\mathrm{NaOH})$ a $1 \%$ por 2 horas (DE SÁ et al., 2012). Amiandamhen e Izekor (2013) constaram efeitos positivos do pré-tratamento de partículas de madeira de Gmelina arbórea com água quente e cloreto de cálcio por período de 24 horas, sobre as propriedades mecânicas dos painéis cimento-madeira. Guimarães et al. (2015) encontraram para painéis cimento-madeira produzidos com clone de E. grandis $x$ E. camaldulensis, aumento no MOE para partículas tratadas com água fria por 24 horas em comparação às partículas tratadas com água quente por 6 horas. Entretanto, os autores não encontraram diferenças significativas entre os dois métodos de pré-tratamentos de partículas para o MOR, absorção de água e inchamento em espessura.

Outros parâmetros importantes no processo de produção de painéis cimento-madeira são a relação cimento:madeira, relação água:cimento e quantidade de acelerador de endurecimento do cimento. Segundo Latorraca (2000), a relação cimento:madeira mais empregada industrialmente é de 1:2,75. Simatupang et al. (1978) relatam que, para manufatura de painéis cimento-madeira de alta massa específica, é utilizada uma proporção de água em relação ao cimento de 0,4 . Os aditivos químicos são empregados normalmente na proporção de $3 \%$ em relação ao peso do cimento. Wang et al. (2016) encontraram para painéis cimento-madeira produzidos a partir de resíduos de construção civil, com relação madeira:cimento de 3:7, relação água:cimento de 0,3 e $2 \%$ de cloreto de cálcio, valores de módulo de ruptura em flexão estática que atendem às normas internacionais.

Várias espécies provenientes de plantios florestais têm sido estudadas para a produção de painéis cimento-madeira, visando fornecer subsídios técnicos para a implantação de indústrias destes painéis no Brasil. Neste contexto, cabe destacar as espécies do gênero Pinus pesquisadas por Lima et al. (2011); espécies de Eucalyptus, por Iwakiri e Prata (2008), Castro et al. (2015) e Iwakiri et al. (2015); além de espécies de madeiras tropicais como Schizolobium amazonicum e Cecropia hololeuca (IWAKIRI et al. (2012) e Gmelina arbórea (AMIANDAMHEN; IZEKOR (2013).

A Hevea brasiliensis é uma espécie arbórea com ocorrência natural restrita à Amazônia brasileira (latitude $7^{\circ} \mathrm{N}$ a $15^{\circ} \mathrm{S}$ ) (LORENZI, 1992). Entretanto, atualmente é cultivada em diversas regiões do País, como nos estados de São Paulo, Espírito Santo, Mato Grosso, Mato Grosso do Sul, Goiás, Bahia e Paraná, além de outros países, como Vietnã, Malásia e Indonésia (GONÇALVES; MARQUES, 2008). A espécie apresenta grande importância econômica para o Brasil pela produção de látex. Uma forma de maximizar a utilização de Hevea brasiliensis provenientes de plantios é por meio da obtenção de produtos múltiplos, sendo que a exploração de madeira tem sido alternativa complementar mais importante, uma vez que pode ser extraída quando o ciclo produtivo de látex é encerrado, como já ocorre em países do sudeste asiático (GONÇALVES et al., 2011).

Tendo em vista a importância do desenvolvimento de novos materiais para a construção civil e, da necessidade de promover espécies alterantivas de rápido crescimento para uso industrial, esta pesquisa teve como objetivo avaliar o potencial de uso da madeira de Hevea brasiliensis (RRIM 600) para produção de painéis cimento-madeira.

\section{MATERIAL E MÉTODOS}

Para a realização desta pesquisa foi utilizada a madeira do clone RRIM 600 da espécie Hevea brasiliensis, com 27 anos de idade, coletadas no Município de Paranapoema, Estado do Paraná. Na composição dos painéis foi utilizado o cimento CP III-40 como aglutinante mineral, cloreto de cálcio e silicato de sódio como aceleradores de endurecimento.

Foram coletadas quatro árvores e três toretes por árvore, os quais foram seccionados em discos com espessura de $30 \mathrm{~mm}$ para obtenção de partículas e amostras para determinação da densidade básica. As partículas foram obtidas com espessura nominal de $0,7 \mathrm{~mm}$, secas ao ar com teor de umidade entre 15 a $20 \%$ e reprocessadas no moinho de martelo para redução nas suas dimensões. A seguir, as partículas foram peneiradas para retirada dos "finos".

O plano experimental consistiu em quatro métodos de pré-tratamentos de partículas (testemunha, imersão em água fria por 24 horas, imersão em água quente por 6 horas e imersão em solução de $1 \%$ de 
hidróxido de sódio por 2 horas), e, dois tipos de aceleradores de cura (cloreto de cálcio e silicato de sódio), conforme apresentado na tabela 1 . O experimento foi conduzido em delineamento inteiramente casualizado, em arranjo fatorial de $4 \times 2$ (métodos de pré-tratamentos de partículas $\mathrm{x}$ aceleradores de endurecimento).

Os painéis, em número de três por tratamento, foram produzidos com dimensões nominais de $505 \times 385 \times 15 \mathrm{~mm}$ (comprimento, largura e espessura), densidade nominal de $1,10 \mathrm{~g} / \mathrm{cm}^{3}$, relação madeira:cimento de 1:2,75, fator água:cimento de 0,40 e 3\% de acelerador de endurecimento do cimento.

Tabela 1. Plano experimental.

Table 1. Experimental plan.

\begin{tabular}{ccc}
\hline Tratamento & Pré-tratamento de partículas & Acelerador de endurecimento \\
T1 & Testemunha & Cloreto cálcio \\
T2 & Imersão água fria - $24 \mathrm{~h}$. & Clicato de sódio \\
T3 & Silicato cálcio de sódio \\
T4 & Imersão água quente $-6 \mathrm{~h}$. & Cloreto cálcio \\
\hline T5 & Silicato de sódio \\
\hline T7 & Imersão NaOH $1 \%-2 \mathrm{~h}$. & Cloreto cálcio \\
T8 & Silicato de sódio \\
\hline
\end{tabular}

O colchão de partículas foi prensado à temperatura ambiente, com pressão específica de $40 \mathrm{kgf} / \mathrm{cm}^{2}$, com três painéis sobrepostos em sequência e mantidos sob restrições no aparato de grampeamento por período de 24 horas para o endurecimento. Após este período, os grampos foram retirados e os painéis foram acondicionados na câmara climática à temperatura de $20 \pm 3{ }^{\circ} \mathrm{C}$ e umidade relativa de $65 \pm 5 \%$, por um período de 28 dias para completa maturação.

Para avaliação das propriedades físicas e mecânicas, foram retirados de cada painel, seis corpos-deprova para ensaios de massa específica aparente, absorção de água e inchamento em espessura após 2 e 24 horas de imersão em água, seis corpos-de-prova para tração perpendicular (ligação interna) e seis corpos-de-prova para flexão estática (módulo de elasticidade e módulo de ruptura). Os ensaios foram realizados de acordo com os procedimentos descritos nas normas EN 317 (2002), EN 319 (2002) e EN 310 (2002), respectivamente.

Os resultados foram submetidos à análise estatística por meio dos testes de kolmogorov-Smirnov e Bartlet para verificação da normalidade e homogeneidade dos dados. Os efeitos dos pré-tratamentos de partículas e tipo de acelerador de cura foi avaliada a partir da análise de variância em arranjo fatorial $(4 \times 2)$ e Teste de médias por Tukey ao nível de probabilidade de $95 \%$.

\section{RESULTADOS}

\section{Propriedades físicas da madeira e dos painéis}

A densidade básica média da madeira de Hevea brasiliensis (Clone RIMM 600) foi de 0,572 $\mathrm{g} / \mathrm{cm}^{3}$, e pode ser considerada de média a baixa densidade, conforme classificação relatada por Mendes et al. (2001). Portanto, a Hevea brasiliensis é uma espécie de madeira com maior densidade em relação à madeira de Pinus, com densidade média em torno de $0,450 \mathrm{~g} / \mathrm{cm}^{3}$ (TRIANOSKI et al. 2013).

Na tabela 2 estão apresentados os valores médios de absorção de água após 2 horas de imersão.

Tabela 2. Valores médios de absorção de água após 2 horas de imersão.

Table 2. Average values of water absorption after 2 hours in water socking.

\begin{tabular}{lcc}
\hline Pré-tratamento & \multicolumn{2}{c}{ Acelerador de endurecimento } \\
\cline { 2 - 3 } & Cloreto de cálcio & Silicato de sódio \\
\hline Ausente & $12,23 \mathrm{aC}(13,88)$ & $19,20 \mathrm{bC}(10,64)$ \\
Água fria & $10,70 \mathrm{aB}(16,46)$ & $17,77 \mathrm{bBC}(11,84)$ \\
Água quente & $9,48 \mathrm{aA}(16,11)$ & $15,52 \mathrm{bA}(13,42)$ \\
Hidróxido de sodio & $9,08 \mathrm{aAB}(15,10)$ & $19,86 \mathrm{bC}(15,04)$ \\
\hline
\end{tabular}

Médias seguidas de mesma letra minúscula na linha e maiúscula na coluna não diferem entre si pelo teste de Tukey ao nível de significância de $5 \%$. Valores entre parêntesis correspondem ao coeficiente de variação.

Os valores médios de absorção de água após 2 horas de imersão em água dos painéis produzidos com cloreto de cálcio variaram de 9,08\% para partículas tratadas com hidróxido de sódio, e 12,23\% para partículas sem tratamento. Para os painéis produzidos com silicato de sódio, os valores médios de absorção de água variaram de 15,52\% para partículas tratadas com água quente, e 19,86\% para partículas tratadas com hidróxido de sódio.

FLORESTA, Curitiba, PR, v. 47, n. 3, p. 289 - 296, jul. / set. 2017

Iwakiri, S. et al.

ISSN eletrônico 1982-4688

DOI: $10.5380 /$ rf.v47i1.51636 
Na tabela 3 estão apresentados os valores médios de absorção de água após 24 horas de imersão.

Tabela 3. Valores médios de absorção de água após 24 horas de imersão.

Table 3. Average values of water absorption after 24 hours in water socking.

\begin{tabular}{lll}
\hline \multirow{2}{*}{ Pré-tratamento } & \multicolumn{2}{c}{ Acelerador de endurecimento } \\
\cline { 2 - 3 } & \multicolumn{1}{c}{ Cloreto de cálcio } & \multicolumn{1}{c}{ Silicato de sódio } \\
\hline Ausente & $16,05 \mathrm{aC}(8,50)$ & $23,04 \mathrm{bC}(7,43)$ \\
Água fria & $13,81 \mathrm{aB}(9,73)$ & $20,23 \mathrm{bBC}(7,74)$ \\
Água quente & $12,44 \mathrm{aA}(9,57)$ & $18,33 \mathrm{bA}(8,51)$ \\
Hidróxido de sodio & $12,52 \mathrm{aAB}(13,36)$ & $23,56 \mathrm{bC}(11,06)$ \\
\hline
\end{tabular}

Médias seguidas de mesma letra minúscula na linha e maiúscula na coluna não diferem entre si pelo teste de Tukey ao nível de significância de $5 \%$. Valores entre parêntesis correspondem ao coeficiente de variação.

Os valores médios de absorção de água após 24 horas de imersão em água dos painéis produzidos com cloreto de cálcio variaram de $12,44 \%$ para partículas tratadas com água quente, e 16,05\% para partículas sem tratamento. Para os painéis produzidos com silicato de sódio, os valores médios de absorção de água variaram de 18,33\% para partículas tratadas com água quente, e 23,56\% para partículas tratadas com hidróxido de sódio.

Na tabela 4 estão apresentados os valores médios de inchamento em espessura após 2 horas de imersão.

Tabela 4. Valores médios de inchamento em espessura após 2 horas de imersão.

Table 4. Average values of thickness swelling after 2 hours in water socking.

\begin{tabular}{lll}
\hline \multirow{2}{*}{ Pré-tratamento } & \multicolumn{2}{c}{ Acelerador de endurecimento } \\
\cline { 2 - 3 } & \multicolumn{1}{c}{ Cloreto de cálcio } & \multicolumn{1}{c}{ Silicato de sódio } \\
\hline Ausente & $0,58 \mathrm{aA}(88,11)$ & $0,94 \mathrm{bA}(72,94)$ \\
Água fria & $0,73 \mathrm{aA}(60,62)$ & $1,32 \mathrm{bAB}(45,99)$ \\
Água quente & $0,54 \mathrm{aA}(59,78)$ & $1,99 \mathrm{bB}(35,25)$ \\
Hidróxido de sodio & $1,21 \mathrm{aB}(21,79)$ & $3,69 \mathrm{bC}(39,02)$ \\
\hline
\end{tabular}

Médias seguidas de mesma letra minúscula na linha e maiúscula na coluna não diferem entre si pelo teste de Tukey ao nível de significância de $5 \%$. Valores entre parêntesis correspondem ao coeficiente de variação.

Os valores médios de inchamento em espessura após 2 horas de imersão em água dos painéis produzidos com cloreto de cálcio variaram de $0,54 \%$ para partículas tratadas com água quente, e 1,21\% para partículas tratadas com hidróxido de sódio. Para os painéis produzidos com silicato de sódio, os valores médios de inchamento em espessura variaram de $0,94 \%$ para partículas sem tratamento e 3,69\% para partículas tratadas com hidróxido de sódio.

$\mathrm{Na}$ tabela 5 estão apresentados os valores médios de inchamento em espessura após 24 horas de imersão.

Tabela 5. Valores médios de inchamento em espessura após 24 horas de imersão.

Table 5. Average values of thickness swelling after 24 hours in water socking.

\begin{tabular}{lcc}
\hline Pré-tratamento & \multicolumn{2}{c}{ Acelerador de endurecimento } \\
\cline { 2 - 3 } & \multicolumn{1}{c}{ Cloreto de cálcio } & Silicato de sódio \\
\hline Ausente & $1,12 \mathrm{aA}(51,38)$ & $1,61 \mathrm{bA}(45,87)$ \\
Água fria & $1,52 \mathrm{aA}(39,90)$ & $2,56 \mathrm{bA}(25,21)$ \\
Água quente & $1,34 \mathrm{aA}(67,70)$ & $2,24 \mathrm{bA}(34,27)$ \\
Hidróxido de sodio & $1,53 \mathrm{aA}(40,00)$ & $3,90 \mathrm{bB}(27,33)$ \\
\hline
\end{tabular}

Médias seguidas de mesma letra minúscula na linha e maiúscula na coluna não doferem entre si pelo teste de Tukey ao nível de significância de 5\%. Valores entre parêntesis correspondem ao coeficiente de variação.

Os valores médios de inchamento em espessura após 24 horas de imersão em água dos painéis produzidos com cloreto de cálcio variaram de 1,12\% para partículas sem tratamento e 1,53\% para partículas tratadas com hidróxido de sódio.

Para os painéis produzidos com silicato de sódio, os valores médios de inchamento em espessura variaram de 1,61\% para partículas sem tratamento e 3,90\% para partículas tratadas com hidróxido de sódio.

\section{Propriedades mecânicas dos painéis}

Na tabela 6 estão apresentados os valores médios de módulo de elasticidade em flexão estática. 
Tabela 6. Valores médios de módulo de elasticidade (MOE) em flexão estática.

Table 6. Average values of the modulus of elasticity (MOE) in static bending.

\begin{tabular}{lcc}
\hline Pré-tratamento & \multicolumn{2}{c}{ Acelerador de endurecimento } \\
\cline { 2 - 3 } & Cloreto de cálcio (MPa) & Silicato de sódio (MPa) \\
\hline Ausente & $2.101 \mathrm{aB}(19,07)$ & $1.250 \mathrm{bB}(17,29)$ \\
Água fria & $3.599 \mathrm{aA}(18,40)$ & $1.941 \mathrm{bA}(22,85)$ \\
Água quente & $3.932 \mathrm{aA}(25,05)$ & $1.502 \mathrm{bA}(26,76)$ \\
Hidróxido de sodio & $2.877 \mathrm{aAB}(22,49)$ & $1.488 \mathrm{bA}(21,82)$ \\
\hline
\end{tabular}

Médias seguidas de mesma letra minúscula na linha e maiúscula na coluna não diferem entre si pelo teste de Tukey ao nível de significância de $5 \%$. Valores entre parêntesis correspondem ao coeficiente de variação.

Os valores médios de módulo de elasticidade (MOE) dos painéis produzidos com cloreto de cálcio variaram de 2.101 MPa para partículas sem tratamento e $3.932 \mathrm{MPa}$ para partículas tratadas com água quente. Para os painéis produzidos com silicato de sódio, os valores médios variaram de $1.250 \mathrm{MPa}$ para partículas sem tratamento e $1.941 \mathrm{MPa}$ para partículas tratadas com água fria.

Na tabela 7 estão apresentados os valores médios de módulo de ruptura em flexão estática.

Tabela 7. Valores médios de módulo de ruptura (MOR) em flexão estática.

Table 7. Average values of the modulus of rupture (MOR) in static bending.

\begin{tabular}{lcc}
\hline Pré-tratamento & \multicolumn{2}{c}{ Acelerador de endurecimento } \\
\cline { 2 - 3 } & Cloreto de cálcio (MPa) & Silicato de sódio (MPa) \\
\hline Ausente & $3,89 \mathrm{aC}(24,05)$ & $0,94 \mathrm{bB}(26,55)$ \\
Água fria & $5,71 \mathrm{aA}(12,56)$ & $2,98 \mathrm{bA}(24,66)$ \\
Água quente & $6,04 \mathrm{aAB}(15,66)$ & $3,23 \mathrm{bA}(25,90)$ \\
Hidróxido de sodio & $4,32 \mathrm{aBC}(18,11)$ & $2,54 \mathrm{bAB}(19,57)$ \\
\hline
\end{tabular}

Médias seguidas de mesma letra minúscula na linha e maiúscula na coluna não doferem entre si pelo teste de Tukey ao nível de significância de 5\%. Valores entre parêntesis correspondem ao coeficiente de variação.

Os valores médios de módulo de ruptura (MOR) dos painéis produzidos com cloreto de cálcio variaram de 3,89 MPa para partículas sem tratamento e 6,04 MPa para partículas tratadas com água quente. Para os painéis produzidos com silicato de sódio, os valores médios variaram de 0,94 MPa para partículas sem tratamento e 3,23 MPa para partículas tratadas com água quente.

Na tabela 8 estão apresentados os valores médios de ligação interna.

Tabela 8. Valores médios de ligação interna.

Table 8. Average values of the internal bond.

\begin{tabular}{lcc}
\hline Pré-tratamento & \multicolumn{2}{c}{ Acelerador de endurecimento } \\
\cline { 2 - 3 } & Cloreto de cálcio (MPa) & Silicato de sódio (MPa) \\
\hline Ausente & $0,46 \mathrm{aA}(21,01)$ & $0,10 \mathrm{bB}(22,65)$ \\
Água fria & $0,53 \mathrm{aA}(19,98)$ & $0,21 \mathrm{bAB}(21,01)$ \\
Água quente & $0,63 \mathrm{aA}(26,80)$ & $0,39 \mathrm{bA}(14,58)$ \\
Hidróxido de sodio & $0,60 \mathrm{aA}(22,56)$ & $0,15 \mathrm{bB}(20,46)$ \\
\hline
\end{tabular}

Médias seguidas de mesma letra minúscula na linha e maiúscula na coluna não diferem entre si pelo teste de Tukey ao nível de significância de 5\%. Valores entre parêntesis correspondem ao coeficiente de variação.

Os valores médios de ligação interna dos painéis produzidos com cloreto de cálcio variaram de 0,46 MPa para partículas sem tratamento e 0,63 MPa para partículas tratadas com água quente. Para os painéis produzidos com silicato de sódio, os valores médios variaram de $0,10 \mathrm{MPa}$ para partículas sem tratamento e 0,39 MPa para partículas tratadas com água quente.

\section{DISCUSSÕES}

A densidade básica média de $0,572 \mathrm{~g} / \mathrm{cm}^{3}$ obtida para a madeira de Hevea brasiliensis situa-se na faixa adequada para produção de painéis particulados de madeira, com a razão de compactação mínima de 1.3, recomendada por Moslemi (1974).

O resultado de absorção de água 2 horas dos painéis produzidos com cloreto de cálcio e partículas tratadas com água quente foi estatisticamente igual aos painéis produzidos com partículas tratadas com hidróxido de sódio e inferior em relação aos demais tratamentos. Os painéis produzidos com silicato de sódio e partículas

FLORESTA, Curitiba, PR, v. 47, n. 3, p. 289 - 296, jul. / set. 2017

Iwakiri, S. et al.

ISSN eletrônico 1982-4688

DOI: $10.5380 /$ rf.v47i1.51636 
tratadas com água quente apresentaram valor médio de absorção de água estatisticamente inferior em relação aos demais tratamentos.

Os painéis produzidos com cloreto de cálcio e partículas tratadas com água quente apresentaram valor médio de absorção de água 24 horas estatisticamente igual aos painéis produzidos com partículas tratadas com hidróxido de sódio e inferior em relação aos demais tratamentos. Os painéis produzidos com silicato de sódio e partículas tratadas com água quente apresentaram valor médio de absorção de água estatisticamente inferior em relação aos demais tratamentos.

Os valores de absorção de água 24 horas de $12,44 \%$ a $23,56 \%$ obtidos para Hevea brasiliensis estão próximos dos valores apresentados na literatura. Iwakiri et al. (2012) encontraram para painéis cimento-madeira de Schizolobium amazonicum e Cecropia hololeuca, valores entre $23,22 \%$ a $25,27 \%$ e de $17,64 \%$ a $20,86 \%$, respectivamente; Iwakiri e Prata (2008) encontraram para painéis de Eucalyptus grandis e Eucalyptus dunnii, valores entre $15,15 \%$ a $20,34 \%$ e $14,27 \%$ a $20,30 \%$, respectivamente; Castro et al. (2015) encontraram para painéis de Eucalyptus saligna, valor médio de $29,11 \%$.

O resultado de inchamento em espessura 2 horas dos painéis produzidos com cloreto de cálcio e partículas sem tratamento e tratadas com água e água fria, apresentaram valor médio estatisticamente igual entre si e superiores em relação aos painéis produzidos com partículas tratadas com hidróxido de sódio. Os painéis produzidos com silicato de sódio e partículas sem tratamento apresentaram valor médio de inchamento em espessura estatisticamente igual aos painéis produzidos com partículas tratadas em água fria, e inferior em relação aos demais tratamentos.

Não foram constatadas diferenças significativas entre os valores médios de inchamento em espessura 24 horas para os painéis produzidos com cloreto de cálcio e diferentes métodos de tratamentos de partículas. Os painéis produzidos com silicato de sódio e partículas sem tratamento, e tratadas em água fria e água quente, apresentaram valores médios de inchamento em espessura estatisticamente iguais entre si, e inferiores em relação aos painéis produzidos com partículas tratadas com hidróxido de sódio.

Em termos comparativos, os resultados de inchamento em espessura 24 horas, de 1,12 a 3,90\%, obtidos para Hevea brasiliensis foram satisfatórios em relação aos valores apresentados na literatura. Iwakiri et al. (2012) encontraram valores entre $1,38 \%$ a $1,95 \%$ e de 0,39 a $0,92 \%$, respectivamente, para painéis produzidos com madeira de Schizolobium amazonicum e Cecropia hololeuca; Latorraca (2000) encontrou para painéis produzidos com Eucalyptus pellita, Eucalyptus robusta, Eucalyptus urophylla e Eucalyptus citriodora, valores entre 1,64\% a 2,12\%; Castro et al. (2015) encontraram para painéis de Eucalyptus saligna, valor médio de 1,47\%; Guimarães et al. (2015) encontraram para painéis produzidos com híbrido de Eucalyptus grandis $x$ Eucalyptus camaldulensis, valor médio de $0,95 \%$. Cabe ressaltar que, todos os painéis produzidos com o cloreto de cálcio, independente de métodos de pré-tratamentos de partículas, atenderam ao requisito máximo de 1,8\% de inchamento em espessura após 24 horas de imersão, conforme as especificações para painéis comerciais produzidos pelo processo BISON (1978).

Tanto para a absorção de água, quanto para o inchamento em espessura, o cloreto de cálcio mostrou ser mais eficiente que o silicato de sódio como acelerador de endurecimento do cimento. Resultados similares para cloreto de cálcio foram obtidos por Amiandamhen e Izekor (2013) para painéis cimento-madeira de gmelina arbórea, e Wang et al. (2016) para painéis produzidos com resíduos de madeiras de construção civil. Além dos aspectos técnicos, a relação custo-benefício do uso de cloreto de cálcio é melhor em comparação aos demais tipos de produtos.

Os painéis produzidos com cloreto de cálcio e partículas tratadas com água quente apresentaram valor médio de MOE estatisticamente igual aos painéis produzidos com partículas tratadas com água fria e hidróxido de sódio, e superiores em relação aos painéis produzidos com partículas sem tratamento. Os painéis produzidos com silicato de sódio e partículas tratadas com água fria, água quente e hidróxido de sódio apresentaram valor médio de MOE estatisticamente iguais entre si, e superiores em relação aos painéis produzidos com partículas sem tratamento.

Os painéis produzidos com cloreto de cálcio como acelerador de endurecimento do cimento, apresentaram valores médios de MOE estatisticamente superiores em relação ao silicato de sódio, para todos os pré-tratamentos de partículas.

Na comparação com as fontes bibliográficas, os resultados de MOE obtidos para painéis de Hevea brasiliensis produzidos com cloreto de cálcio, estão próximos dos apresentados por Latorraca (2000) para quatro espécies de Eucalipto - E. pellita, E. robusta, E. urophylla e E. citriodora, com valores entre $1.840 \mathrm{MPa}$ a 3.390 MPa. Iwakiri et al. (2012) encontraram para painéis de Schizolobium amazonicum e Cecropia hololeuca, valores de MOE de $2.571 \mathrm{MPa}$ e $2.836 \mathrm{MPa}$; e, Castro et al. (2015) encontraram para painéis de Eucalyptus saligna, valor médio de $2.522 \mathrm{Mpa}$; Amiandamhen e Izekor (2013) encontraram para painéis produzidos com Gmelina arbórea, valor médio de $1.897 \mathrm{MPa}$. 
Os painéis produzidos com cloreto de cálcio e partículas tratadas com água fria e água quente foram os que atenderam ao requisito mínimo para MOE de 3.000 MPa estabelecido pelo processo BISON (1978) para painéis comerciais de cimento-madeira.

Os painéis produzidos com cloreto de cálcio e partículas tratadas com água quente apresentaram valor médio de MOR estatisticamente igual aos painéis produzidos com partículas tratadas com água fria, e superiores em relação aos painéis produzidos com partículas sem tratamento e tratadas com hidróxido de sódio. Os painéis produzidos com silicato de sódio e partículas tratadas com água quente, água fria e hidróxido de sódio apresentaram valores médios de MOR estatisticamente iguais entre si, e superiores em relação aos painéis produzidos com partículas sem tratamento.

Os painéis produzidos com cloreto de cálcio apresentaram valores médios de MOR estatisticamente superiores em relação ao silicato de sódio, para todos os pré-tratamentos de partículas.

Os resultados obtidos foram inferiores ao valor mínimo de 9,0 MPa, conforme as especificações para painéis comerciais produzidos pelo processo BISON (1978). Quanto aos resultados apresentados na literatura, Latorraca (2000) obteve para painéis de E. pellita, E. robusta, E. urophylla e E. citriodora, valores de MOR entre 3,53 MPa a 6,77 MPa; Castro et al. (2015) encontraram para painéis de E. saligna, valor médio de 4,02 MPa; Iwakiri e Prata (2008) encontraram para painéis de E. dunnii valores entre 3,53 MPa a 4,02 Mpa; Amiandamhen e Izekor (2013) encontraram para painéis de Gmelina arbórea, valor médio de 6,90 MPa. Portanto, os painéis cimento-madeira de Hevea brasiliensis apresentaram resultados satisfatórios de MOR em comparação aos valores apresentados por vários pesquisadores.

Não foram constatadas diferenças significativas para a ligação interna, entre os painéis produzidos com cloreto de cálcio e diferentes métodos de pré-tratamentos de partículas. Os painéis produzidos com silicato de sódio e tratadas com água quente apresentaram valor médio de ligação interna estatisticamente igual aos painéis produzidos com partículas tratadas em água fria, e superiores em relação aos painéis produzidos com partículas sem tratamento e tratadas com hidróxido de sódio.

Os painéis produzidos com cloreto de cálcio como acelerador de endurecimento do cimento apresentaram valores médios de ligação interna estatisticamente superiores em relação ao silicato de sódio, para todos os pré-tratamentos de partículas.

Na comparação com os dados apresentados na literatura, os resultados obtidos para Hevea brasiliensis foram satisfatórios aos valores médios obtidos por Iwakiri e Prata (2008) para painéis cimento-madeira de $E$. grandis na faixa de 0,24 MPa a 0,47 MPa e, aos resultados apresentados por Santos et al. (2012) para painéis produzidos com Pinus taeda com misturas de 25, 50 e 75\% de Eremanthus erythropappus, de 0,60 MPa, $0,68 \mathrm{MPa}$ e 0,54 MPa, respectivamente. Todos os resultados de ligação interna obtidos para os painéis produzidos com cloreto de cálcio como acelerador de endurecimento atenderam ao requisito mínimo de 0,40 MPa estabelecido pelo Processo BISON.

\section{CONCLUSÕES}

- Constatou-se a eficiência do pré-tratamento de partículas nas propriedades dos painéis cimento-madeira, sendo que o tratamento mais eficiente foi o de imersão em água quente. Isso se deve ao fato de que este prétratamento elimina os principais tipos de extrativos inibidores de endurecimento do cimento presentes na madeira.

- O Cloreto de cálcio apresentou elevada eficácia como acelerador de endurecimento do cimento, tendo em vista que foi estatisticamente superior ao Silicato de sódio em todos os ensaios físicos e mecânicos, além de atingir os requisitos estabelecidos para painéis comerciais produzidos pelo processo BISON na maioria das propriedades avaliadas. Em termos de aplicações, recomenda-se, quando necessário, o uso de parafusos galvanizados ou de aço inox para as eventuais necessidades de fixação dos painéis, devido à sua reação corrosiva com o aço.

- A madeira de Hevea brasiliensis (Clone RRIM 600) apresenta potencial para produção de painéis cimentomadeira, com cloreto de cálcio como acelerador de endurecimento do cimento, uma vez que os resultados obtidos em grande parte atenderam aos requisitos estabelecidos para painéis comerciais produzidos pelo processo BISON.

\section{REFERENCIAS}

AMIANDAMHEN, S. O.; IZEKOR, D. N. Effect of wood particle geometry and pre-treatments on the strength and sorption properties of cement-bonded particleboards. Journal of Applied and Natural Science, v. 5, n. 2, p. 318-322, 2013.

FLORESTA, Curitiba, PR, v. 47, n. 3, p. 289 - 296, jul. / set. 2017 
BISON. Wood-cement board. Berlin: Springer, 1978. 10p.

CASTRO, V. G.; BRAZ, R. L.; AZAMBUJA, R. R.; LOYOLA, P. L.; IWAKIR, S.; MATOS, J. L. M. Painéis cimento-madeira de Eucalyptus saligna com diferentes aditivos químicos e métodos de formação. Floresta, Curitiba, v. 45, n. 2, p. 349-360, 2015.

DE SÁ, V. A.; BUfAlinO, L.; ALBINO, V. C. S.; CORRÊA, A. A.; MENDES, L. M.; ALMEIDA, N. A. Mistura de três espécies de reflorestamento na produção de painéis cimento-madeira. Revista Árvore, Viçosa, v. 36, n. 3, p. 549-557, 2012.

EUROPEAN COMITEE FOR STANDARDIZATION - CEN. EN 310. Wood based panels - Determination of modulus of elasticity in bending and of bending strength. 2002.

EUROPEAN COMITEE FOR STANDARDIZATION - CEN. EN 317. Wood based panels - Determination of swelling in thickness after immersion in water. 2002.

EUROPEAN COMITEE FOR STANDARDIZATION - CEN. EN 319. Aglomerado de partículas de madeira e de fibras de madeira. Determinação da resistência à tração perpendicular às faces da placa. 2002.

GONÇALVES, P. de S.; MARQUES, J. R. B. Melhoramento genético da seringueira: passado, presente e futuro. In: AlVARENGA, A. P.; CARMO, C. A. F. S. (Ed.). Seringueira. Viçosa, MG: Epamig, 2008. p. 399-534.

GUIMARÃES, J. C. O.; LIMA, J. T. C.; NUNES, J. S.; LISBOA, F. J. N.; GUIMARÃES JR, J. B. Eficiência do tratamento de partículas de eucalipto do híbrido de E. grandis X E. camaldulensis para produção de painéis minerais. Enciclopédia Biosfera, v. 11, n. 21, p. 949-955, 2015.

IWAKIRI, S.; PRATA, J. G. Utilização de madeira de Eucalyptus gandis e Eucalyptus dunnii na produção de painéis cimento-madeira. Cerne, v. 14, p. 68-74, 2008.

IWAKIRI, S.; TRIANOSKI, R.; BONDUELLE, G. M.; ROCHA, V. Y. Avaliação do potencial de utilização da madeira de Schizolobium amazonicum "paricá" e Cecropia hololeuca "Embaúba" para produção de painéis cimento-madeira. Cerne, v. 18, p. 32-39, 2012.

IWAKIRI, S.; TRIANOSKI, R.; CUNHA, A. B.; PRATA, J. G.; HARA, M.; BILA, N. F.; LUIS, R. C. G.; ARAÚJO, R. D. Propriedades tecnológicas de painéis cimento-madeira produzidos com partículas de eucalipto. Revista de Ciências Agroveterinárias, v. 14, p. 217-223, 2015.

LATORRACA, J. V. F. Eucalyptus spp. na produção de painéis de cimento madeira. 2000. 191f. Tese (Doutorado em Ciências Florestais) - Universidade Federal do Paraná, Curitiba, 2000.

LIMA, A. J. M.; IWAKIRI, S.; RAMIREZ, M. G. Utilização de resíduos de pinus spp., metacaulim de alta reatividade e resíduo de cerâmica calcinada em compósitos cimento-madeira. Madera y Bosques, v. 17, p. 47$65,2011$.

LORENZI, H. Árvores brasileiras: manual de identificação e cultivo de plantas arbóreas nativas do Brasil. Nova Odessa: Plantaraum, 1992. 302p.

MENDES, L. M.; SILVA, J. R. M.; TRUGILHO, P. F.; LIMA, J. T. Densidade da madeira de Pinus oocarpa Schiede no sentido longitudinal dos caules. Cerne, v. 5, n. 1, 2001.

MOSLEMI, A. A. Particleboard. Illinois: Southern Illinois University, 1974. 244p.

SANTOS, R. C.; CARnEIRO, A. C. C.; CASTRO, A. F. N. M.; CASTRO, R. V. O.; PIMENTA, A. S.; ARAÚJO, S. O.; ATAÍDE, G. M. Efeito inibidor da madeira de candeia em mistura com aglutinantes minerais. Scientia Forestalis. v. 40, n. 93, p. 113-140. 2012.

SIMATUPANG, M. H.; SCHWARZ, G. H.; BROOKER, F. W. M. H. Small scale plants for the manufacture of mineral-bonded wood composites. In: World Forestry Congress, Jakarta: 1978, 21p.

TRIANOSKI, R.; MATOS, J. L. M.; IWAKIRI, S.; PRATA, J. G. Avaliação da estabilidade dimensional de espécies de pinus. Floresta e Ambiente, v. 20, n. 3, p. 398-406, 2013.

WANG, L.; CHEN, S. S.; TSANG, D. C. W.; POON, C. S.; SHIH, K. Value-added recycling of construction waste wood into noise and thermal insulating cement-bonded particleboards. Construction and Building Materials, v. 125, p. 316-325, 2016. 